\section{LOS LÍMITES POLÍTICOS DE LA AUTONOMÍA LOCAL: GRANADA, 1899}

\author{
Álvaro López Osuna \\ Universidad de Granada \\ alvak@gmail.com
}

\section{The political boundaries of local autonomy: Granada, 1899}

Recibido: 16/6/2016 - Aceptado: 01/04/2016

Cómo citar este artículo/Citation:

Álvaro LÓPEZ OSUNA (2017), “Los límites políticos de la Autonomía local: Granada, 1899”, Hispania Nova, 15, págs. 24 a 44 .

DOI: https://doi.org/10.20318/hn.2017.3479
Copyright: (c) HISPANIA NOVA es una revista debidamente registrada, con ISSN 1138-7319 y Depósito Legal M 9472-1998. Los textos publicados en esta revista están -si no se indica lo contrario- bajo una licencia Reconocimiento-Sin obras derivadas 3.0 España de Creative Commons. Puede copiarlos, distribuirlos y comunicarlos públicamente siempre que cite su autor y la revista y la institución que los publica y no haga con ellos obras derivadas. La licencia completa se puede consultar en: http://creativecommons.org/licenses/by-nd/3.0/es/deed.es
Resumen: El presente artículo intenta acometer el episodio de protesta acontecido en la ciudad de Granada a raíz de la suspensión gubernativa de catorce concejales pertenecientes a la minoría opositora del ayuntamiento en diciembre de 1899 por el gabinete presidido por Francisco Silvela. Para ello, en primer lugar, se analiza, a partir del concepto de contienda política aportado por Charles Tilly, Sidney Tarrow y Douglas McAdam, las causas o antecedentes de la inahabilitación, las cuales radicaron en los profundos desajustes institucionales acontecidos en la política local. En segundo lugar, se enmarcan las movilizaciones en favor de la restitución de los ediles granadinos en el contexto finisecular regeneracionista, sus momentos y consecuencias.

Palabras clave: Autonomía local, contienda política, protesta, Restauración, Granada.

\begin{abstract}
This article tries to rush episode protest occurred in the city of Granada following the gubernatorial suspension of fourteen councilors belonging to the minority opposition city council in December 1899 by the cabinet chaired by Francisco Silvela. To do this, first, it analyzed, based on the concept of political contention provided by Charles Tilly, Sidney Tarrow and Douglas McAdam, causes or history of the disqualification, which settled in the deep institutional mismatches occurred in local politics. Secondly, the demonstrations are framed in favor of the restitution of councilors grenadians in the regeneracionista finisecular context, moments and consequences.
\end{abstract}

Key words: Local autonomy, political contention, protest, Restoration, Granada. 


\section{LOS LÍMITES POLÍTICOS DE LA AUTONOMÍA LOCAL: GRANADA, 1899}

\section{INTRODUCCIÓN}

Desde el comienzo de la Restauración hasta finales del siglo XIX, la vida municipal en la ciudad de Granada transcurrió sin mayores complicaciones, siguiendo los rutinarios cauces en el traspaso de poder entre conservadores y liberales que establecía el turno de partidos ${ }^{1}$. Esta apacible dinámica general, que incluía el amigable reparto de actas en el distrito en virtud del encasillado acordado por los prohombres de la política local y los líderes dinásticos nacionales en cada convocatoria a Cortes, vino a alterarse por vez primera en las elecciones generales y locales de 1899. De una parte, por la ruptura de la combinación oficial que otorgaba la primacía por el distrito a los partidos de gobierno; de otro lado, por la incapacidad del partido en el ejercicio del poder, la Unión Conservadora de Francisco Silvela, de obtener una mayoría solvente tras las municipales. En ambos procesos electorales jugó un papel determinante la irrupción en el juego político de la Liga Agraria ${ }^{2}$ : la asociación patronal de defensa de los intereses agrícolas de la provincia, que a comienzos del verano inició una sonada campaña de protesta en contra de la liberalización del sector azucarero en España.

La composición de este inesperado escenario puso en cuestión otro aspecto, si cabe, de más profundo alcance: la imposibilidad de monopolizar el conjunto de los resortes político-administrativos del cabildo por parte de los silvelistas, entre los cuales ocupaba un lugar destacado el control del presupuesto y la Hacienda local. De esta forma, quedaban bloqueados los canales que alimentaban el extenso entramado tentacular que hacia virar la rueda de la vieja política. Frente a este adverso panorama, los detentadores del poder local intentaron revertir la situación mediante dos medidas. En primer lugar, anulando los resultados electorales, cuestión que no fue avalada por la junta electoral. En segundo lugar, fracasada esta tentativa, aprovecharon la aprobación de una moción de las minorías en

\footnotetext{
${ }^{1}$ Antonio LARA RAMOS, "La política granadina durante el reinado de Alfonso XII", Anuario de Historia Moderna y Contemporánea, №14, 1987-1991, pp.67-86. Una exposición general en Juan GAY ARMENTEROS y Cristina VIÑES MILLET, Historia de Granada. La época contemporánea. Siglos XIX y XX, Tomo IV, Granada, Don Quijote,1982, pp.277-319; Miguel GÓMEZ OLIVER y Salvador CRUZ ARTACHO, "Granada en la Edad Contemporánea", en Antonio MALPICA CUELLO, Luis CORTÉS PEÑA y Miguel GÓMEZ OLIVER (coord.), Historia de Granada, Granada, Proyecto Sur,1996, pp. 181-352.

2 La Liga Agraria de Granada se fundó a finales de 1887, absorbiendo las antiguas atribuciones de la Liga de Contribuyentes. Ambas fueron presididas por el Marqués de Dílar, Pablo Díaz y Jiménez. Su constitución en El Defensor de Granada, 7-11-1887, "En el ayuntamiento". Algunas notas sobre su carácter y fines en Luis GONZÁLEZ RUIZ, Origen y desarrollo del cultivo del tabaco en la provincia de Granada (1870-1960), Tesis, Universidad de Granada 1998, Vol. I, p.113.
} 
el consistorio, en la que se reprobaba a un diputado ministerial de la circunscripción para provocar la suspensión gubernamental de los opositores.

La injusta medida dio lugar a la organización de una campaña de repulsa en solidaridad con los ediles desplazados de su cargo. Las acciones de protesta se materializaron con la organización de banquetes en los que los protagonistas pronunciaron abundantes discursos. Los ecos de la movilización iniciada trascendieron los límites provinciales, captando la atención de un amplio sector de la prensa de toda la nación. El desenlace de la crisis, que se saldó con la reposición en sus puestos de los munícipes sancionados, ocasionó la dimisión del jefe del denominado Partido Silvelista y la separación de la facción de un importante número de notables locales.

Creemos que dichos sucesos, y el grueso de movilizaciones acontecidas en Granada en favor de los ediles apartados por la acción gubernativa, poseen una relevancia significativa al establecerse como un ejemplo de las colisiones entre política institucional y régimen local en España en el contexto posterior a la crisis del 98. Sin embargo, no han sido tratados con profundidad por los estudios historiográficos locales existentes sobre la Restauración en la ciudad nazarí ${ }^{3}$. Por ello, nuestro análisis de los hechos se desarrolla en atención a un doble planteamiento con el que se intenta explicar y vincular las causas como sus consecuencias directas. Primero, a una escala micro, se intenta fundar el origen de las crisis, cuyo epicentro giró en derredor del ámbito de la política institucional, relacionando las perturbaciones ocasionadas por las coyunturales modificaciones de la política oligárquica por la aparición de una tercera fuerza, la división en las filas del Partido Conservador y la distorsión en la competencia electoral.

Segundo, a un nivel macro, de manera conjugada, realizar una lectura que aborde la intervención del poder central en la esfera local, cifrado en el interesado restablecimiento de la mayoría favorable del partido dinástico de turno. Por otro lado, acometer una visión que incida en el contexto general de las limitaciones de la democratización del régimen canovista que ponía el foco en el mundo local, por el caciquismo. Todo ello, enmarcado o conectado con el espíritu crítico finisecular propiciado por el regeneracionismo, que puso el acento en las urgentes necesidades de reforma del sistema.

El planteamiento inicial o génesis de la crisis, referente a la lucha electoral y el episodio de protesta impulsado por el trust del azúcar, se acomete empleando las aportaciones conceptuales introducidas en el estudio de la política institucional y acción colectiva por autores como Charles Tilly, Sidney Tarrow y Douglas McAdam ${ }^{4}$. Los planteamientos de esta pléyade de autores, nos permite pensar que es posible entrelazar fenómenos de política convencional con prácticas no institucionales; pues, en multitud de ocasiones, ambos fenómenos son el resultado de un mismo proceso político. Para desarrollar esta primera fase del objeto de estudio, empleamos el concepto de contienda política con el que se intenta trascender la ficticia separación entre política rutinaria (actos de partido, elecciones,

\footnotetext{
3 Una excepción a este vacío en Álvaro LÓPEZ OSUNA, Dinámica de la contienda política en la ciudad de Granada, 1898-1923, Tesis, Universidad de Granada, Granada, 2014, pp.272-274.

${ }^{4}$ Las más destacadas son: Charles TILLY, From Mobilization to Revolution, New York, Ramdom House, 1978; Grandes estructuras, procesos amplios, comparaciones enormes, Madrid, Alianza, 1991; Las revoluciones europeas, 1492-1992, Barcelona, Crítica, 1995. El siglo rebelde, Zaragoza, Prensas Universitarias de Zaragoza, 1997; Violencia colectiva, Barcelona, Hacer, 2007 (a); Contienda política y democracia en Europa 1650-2000, Barcelona, Hacer, 2007 (b); Explaining Social Processes, Boulder (Co), Paradigm Publishers, Boulder, 2008; Sidney TARROW, El poder en movimiento: los movimientos sociales, la acción colectiva y la política, Madrid, Alianza, 2004. Douglas MCADAM, Freedom summer, New York, University Press, 1990.
} 
etc.) y política no convencional (agitaciones, algaradas, motines). Por contienda política los autores entienden:

"La interacción episódica, pública y colectiva entre los reivindicadores y sus objetos cuando: (a) al menos un gobierno es uno de los reivindicadores, de los objetos de las reivindicaciones o es parte en las reivindicaciones, y (b) las reivindicaciones, caso de ser satisfechas, afectarían a los intereses de al menos uno de los reivindicadores ${ }^{5}$ ".

La segunda parte del estudio, relativa a la suspensión de la minoría opositora en el Ayuntamiento de Granada, se enfrenta mediante una contextualización general de la crisis en la que entró el sistema en los años finiseculares. De todas las reformas que demandaba el sistema la de la administración local era la más perentoria, al establecerse el municipio como el eslabón fundamental del entramado caciquil. Asimismo, se emplea el concepto de repertorio establecido por los autores de la Dinámica de la contienda para delimitar los actores, modos y momentos por los que atravesó la protesta.

La descripción y análisis de los hechos se acomete mediante el análisis de dos clases de fuentes primarias: de una parte, la consulta de siete cabeceras de prensa tanto locales como nacionales; de otro lado, las Actas de la Comisión Municipal Permanente existentes en el Archivo Municipal de Granada $(\mathrm{AMG})^{6}$.

En consecuencia, este artículo queda estructurado en un primer epígrafe, donde se analiza la aparición e incidencia que provocó la entrada en la escena política de Granada de la Liga Agraria; en segundo lugar, las repercusiones que ocasionó el inicio de un ciclo de protesta inducido por los "azucareros" contra el gabinete presidido por Silvela; en tercer lugar, se acomete la suspensión de las minorías en el cabildo granadino y la campaña de descargo en pos de la reposición de los sancionados en el contexto del 98. Por último, de manera breve, se realiza un balance de lo sucedido y sus consecuencias.

\section{LA ENTRADA EN ESCENA DE LA LIGA AGRARIA}

\section{Partidos y política en Granada en los años previos al Desastre}

El elemento denotativo con el que puede caracterizarse el ámbito institucional en la ciudad de Granada en el periodo que transcurrió entre el inicio de la Restauración y finales de centuria, fue el hegemónico control que del proceso político mantuvieron los partidos dinásticos. Sin duda, en la configuración de un escenario tan estable y factible para los intereses de los partidos de gobierno, jugó un papel de singular trascendencia la combinación de una serie de factores de carácter endógeno como exógeno que hicieron posible su dominio. Con respecto al primero de los elementos mencionados, hay que señalar el mantenimiento de unas jefaturas tan incontestadas como duraderas, que cohesionaron y dotaron de unidad de acción a sendas formaciones.

\footnotetext{
${ }^{5}$ Douglas MCADAM, Sidney TARROW y Charles TILLY, Dinámica de la contienda política, Barcelona, Hacer, 2005, p.5.

${ }^{6}$ Con respecto a la prensa se han consultado: El Defensor de Granada, La Publicidad, Heraldo Granadino, El Imparcial, Heraldo de Madrid, El Liberal y El País.
} 
En el caso del Partido Conservador, las disensiones internas no comenzaron a vislumbrarse hasta el fallecimiento del líder local Eduardo Rodríguez Bolívar en abril de 1897. La desaparición de Bolívar, que era el elemento aglutinador entre las distintas corrientes que componían el conservadurismo granadino, unido al inesperado asesinato de Cánovas cuatro meses después, impidió el consenso en torno a una única figura preeminente. En su lugar, la agrupación quedó dividida en torno a tres corrientes o familias, en simbiosis con las pugnas que mantenían en Madrid Francisco Silvela, Carlos O’Donell (Duque de Tetuán) y Francisco Romero Robledo por ocupar la dirección vacante.

La facción mayoritaria en Granada, al igual que en el resto de la nación, fue la auspiciada por Silvela, a cuyo encargo quedó Vicente Cabeza de Vaca y Fernández de Córdoba (Marqués de Portago), que recibía el apoyo ministerial en las elecciones a Cortes. En la capital, el liderazgo del Partido Silvelista fue entregado a Mariano Agrela y Moreno (Conde de Agrela) ${ }^{7}$. En relación a las dos facciones disidentes con el oficialismo, los seguidores del Duque de Tetuán o "tetuanistas" fueron acaudillados por el insigne banquero y futuro líder del Partido Conservador Manuel Rodríguez-Acosta de Palacios ${ }^{8}$. Por otro lado, desempeñando un papel muy minoritario, se encontraban los "romeristas"; pequeña fracción que representaba los intereses de Francisco Romero Robledo en la ciudad. Su liderato estaba en manos de Juan Hurtado. Solo presentaban candidaturas en las elecciones municipales en aquellos distritos con los que contaban con abundantes simpatías.

En relación al Partido Liberal, la adhesión de los fusionistas granadinos en torno a la figura de Sagasta fue mayoritaria hasta su desaparición de la escena política a comienzos de 1903. A finales de siglo, la personalidad más destacada en la circunscripción seguía siendo Alberto Aguilera y Velasco, si bien su influencia comenzó a declinar en sintonía con su progresivo alejamiento de la política provincial ${ }^{9}$. El jefe nominal del partido era el opulento capitalista Pedro N. Mirasol de la Cámara.

En contraposición al oficialismo existía, por una parte, una pequeña facción de "gamazistas" dirigidos por el Conde de las Infantas, que siguiendo los dictados de Germán Gamazo se habían separado de la disciplina de la agrupación matriz en las postrimerías del $98^{10}$. De otro lado, el grupo de los liberal-demócratas o "canalejistas", más escorados a la izquierda, que hacían la política de José Canalejas en la ciudad. Su líder era el catedrático de Fisiología de la Universidad de Granada Federico Gutiérrez.

En segundo lugar, de carácter exógeno, hay que constatar la inexistencia de una sólida contestación que discutiera el monopolio de gobierno al bloque de poder constituido por

\footnotetext{
${ }^{7}$ Antonio PAREJA (coord.), Grandes empresarios andaluces, Madrid, LID, 2011, Vol.I, p.361.

${ }^{8}$ Era dueño de la Banca Rodríguez-Acosta, presidente del Consejo Provincial de Industria y Comercio de Granada y consejero de la Sociedad General Eléctrica del Sur, de la Sociedad General del Azúcar (SGA) y de la constructora la Reformadora Granadina, empresa encargada de construir la Gran Vía de Granada. Manuel TITOS MARTíNEZ, Rodríguez Acosta. Banqueros granadinos 1831-1946, Madrid, Lid Editorial, 2004.

${ }^{9}$ Su distanciamiento de la política provincial quedo patente tras su nombramiento en 1901 como alcalde de Madrid, distinción que repitió en 1906 y 1909. José JULIO GARCÍA, Alberto Aguilera, alcalde de Madrid (su personalidad, su obra y su tiempo), Madrid, Artes Gráficas Municipales, 1989.

${ }^{10}$ La ruptura entre Germán Gamazo y Sagasta conllevó la salida del grupo liberal de noventa diputados, que pasaron a actuar como independientes. Sus líderes más destacados eran Antonio Maura (cuñado de Gamazo) y José Sánchez-Guerra". En 1901, ambos, se pasaron al Partido Conservador. Esther CALZADA DEL AMO, Germán Gamazo (1840-1901). Poder político y redes sociales en la Restauración, Madrid, Marcial Pons, 2011.
} 
conservadores y liberales, debido a la atomización y desarticulación en que estaban sumidas las fuerzas antidinásticas que se parapetaban a extramuros del sistema. En este sentido, el republicanismo, principal núcleo de oposición desde la finalización de la I República, había quedado atomizado en un sinfín de grupos y grupitos. La división en sus filas obedecía a diferencias tanto de forma (división territorial del Estado, orden público o reforma social) como de fondo (programa, objetivos, táctica) ${ }^{11}$, llegando a coexistir en Granada hasta cinco agrupaciones distintas a finales de siglo. La dirección de estas formaciones estaban lideradas por venerables personalidades que habían participado en el Sexenio Revolucionario. Así, el Partido Republicano Centralista estaba acaudillado por expresidente Nicolás Salmerón. La dirección de los centralistas en Granada estaba encomendada a Antonio Ocete. Era el grupo que contaba con menos simpatías y prosélitos dentro de las diferentes familias que componían el republicanismo granadino. Su posición política estaba cercana a los intereses de la mediana burguesía, estando por "temperamento e ideas en la derecha republicana" ${ }^{12}$.

Por otro lado, se situaban los seguidores del Partido Republicano Progresista, herederos del legado político de Manuel Ruiz Zorrilla. Su jefe local era Miguel Garrido Atienza. Por norma general optaban por el retraimiento electoral, contando con un reducido núcleo de seguidores. A consecuencia de la batalla abierta por el control del partido tras la muerte de Zorrilla en 1895, el partido sufrió una escisión tras ser elevado a la nueva jefatura el doctor José María Esquerdo. Un grupo minoritario discrepante encabezado por José Muro, decidió fundar el Partido Republicano Nacional. Su jefatura en Granada, de manera honoraria, la desempeñaba el respetado republicano Pablo Jiménez González, aunque la dirección la ejercía el Catedrático de Medicina de la Universidad Rafael García-Duarte González.

Siguiendo los dictados de Francisco Pi y Margall, se situaban los miembros del Partido Republicano Federal. En Granada era la facción que contaba con mayor número de seguidores ${ }^{13}$. Su figura más insigne era Ramón Maurell. Como presidente del comité ejecutivo del partido se situaba Romualdo Ruiz Zalabardo, antiguo comandante del Batallón de Voluntarios durante la proclamación del cantón en el verano de 1873. En contraposición a los grupos anteriores, los más próximos al sistema eran los miembros del antiguo Partido Republicano Posibilista de Emilio Castelar. Su personalidad más destacada en Granada era el Catedrático de Economía de la Abadía del Sacromonte Amando Castroviejo. Su programa político quedó cubierto tras la concesión de Sagasta del derecho al sufragio universal en 1890. Por lo que, la mayoría de sus miembros se integraron en el Partido Liberal ${ }^{14}$.

El resto de formaciones opuestas al turno de partidos y a la legitimidad política emanada de la constitución de 1876, carecían de una mínima organización y consistencia a la altura del 98 . De este

\footnotetext{
11 Carlos DARDÉ MORALES, “La larga noche de la Restauración, 1875-1900”, en Nigel TOWNSON (ed.), EI republicanismo en España (1830-1977), Madrid, Alianza Editorial, 1994, pp.113-138; Antonio ROBLES EGEA y Manuel MENÉNDEZ ALZAMORA, “EI republicanismo durante la Restauración" en Manuel MENÉNDEZ ALZAMROA y Antonio ROBLES EGEA (ed.), Pensamiento político en la España contemporánea, Madrid, Trotta, 2013, pp.247-270.

${ }^{12}$ Las palabras entrecomilladas con las que se definía su línea ideológica en El Defensor de Granada, 18-2-1902, “EI banquete de los republicanos".

${ }^{13}$ Su número de afiliados en el último lustro del siglo XIX ascendía a de 3.338. El Defensor de Granada, 20-1-1896, "Los federales".

${ }^{14}$ Una visión más extensa de estos grupos en Álvaro LÓPEZ OSUNA, “EI republicanismo en la ciudad de Granada (1898-1908): Acción colectiva y dinámica electoral”, Sociedad y Utopía, №38, 2011, pp.25-44.
} 
modo, las organizaciones que se posicionaban a la derecha del sistema no pasaban de ser partidos constituidos por una junta nominal que realizaban esporádicas reuniones de propaganda y no concurrían a las elecciones. El único medio de propagar su ideario se reducía a la publicación de diarios de corta tirada y escasa difusión. Los carlistas granadinos contaban con el periódico La Verdad y en el plano social con el efímero semanario El Amigo del Obrero. En el caso del Partido Católico Nacional o Partido Integrista disponía del diario El Triunfo $^{15}$. En cierta medida, como los definía la prensa generalista, no eran más que "ficciones incorpóreas". A la izquierda, la situación no era muy distinta, el Partido Socialista en Granada, cuya fundación se había producido tras la elevación de un manifiesto a la opinión el 11 de febrero de 1892, estaba constituido por un grupúsculo de obreros. Sus únicas actuaciones se limitaban a la celebración de pequeños actos de propaganda en conmemoración del 1으 de Mayo ${ }^{16}$.

En ese contexto político de fin de siglo, aparentemente tan poco propicio para la aparición de nuevas formaciones por la hegemonía ejercida por conservadores y liberales del campo político, nació la Liga Agraria a comienzos de $1898^{17}$. A este respecto, hay que matizar que, la Liga no era un partido político sino una agrupación de notables locales; ya que carecía de ideario, estructuras orgánicas de elección de sus miembros, y no disponía de militancia. En puridad, puede considerarse como una carcasa organizativa en la que confluían las distintas personalidades que componían el reducido grupo de grandes propietarios fabriles vinculados a la industria del azúcar de Granada. Cuyo único fin fue la defensa de los intereses gremiales de un cerrado círculo de poderosos financieros e industriales.

En función de esta asociación de intereses económicos, no era más que una extensión política de la asociación patronal original, recayendo su jefatura en su fundador, el Marqués de Dílar, influyente propietario y primer presidente de la Cámara de Comercio, Industria y Navegación de Granada. Junto a él ingresaron una nutrida nómina de terratenientes entre los cuales descollaban las figuras de Julio Quesada-Cañaveral y Piedrola (Conde de Benalúa) ${ }^{18}$, Juan López-Rubio Pérez y Juan Ramón La Chica y Mingo.

\section{Comportamiento y dinámica electoral: Los comicios generales y municipales de 1899}

A finales del año anterior habían cesado en el poder los liberales de Sagasta, agotados tras el desastre cubano y la firma del Tratado de París con los Estados Unidos, propiciando la ascensión a la presidencia del Consejo de Ministros de la Unión Conservadora de Francisco Silvela. Las alternancias desde el comienzo de la Restauración siempre fueron un puro artificio, a pesar de que la constitución del 76 establecía que debían producirse mediante elecciones al establecerse como la base legal del sistema, puesto que eran prerrogativas de la Corona el designar el gobierno; estableciéndose como

\footnotetext{
${ }^{15}$ Andrés MANJÓN CABEZAS y Antonio SÁNCHEZ, Guía de la prensa de Granada y provincia (1706-1989), Granada, Hemeroteca del Museo de la Casa de los Tiros, 1995.

${ }^{16}$ Los comienzos del PSOE en Granada en Antonio Ma CALERO AMOR, El movimiento obrero en Granada, 19091923, Madrid, Tecnos, 1973; James R. LEVY, "Notes on how to start a political party: The socialists of Granada, 1890-1895", Journal of Iberian and Latin American Research, №8:1, 2002, pp.1-34.

${ }^{17}$ El Defensor de Granada, 10-2-1898 y 25-1-1899, “La Liga Agraria”.

${ }^{18}$ El Conde de Benalúa, al que añadió pocos años después por designación real el título de Duque de San Pedro de Galatino, fue amigo personal de Alfonso XIII y un afamado empresario que destacó por sus brillantes iniciativas en el desarrollo turístico de Granada: constructor del Hotel Alhambra Palace (1910) e impulsor de la carretera a Sierra Nevada. Manuel TITOS MARTínEZ, El Duque de San Pedro de Galatino, Granada, Comares, 1999.
} 
norma común, casi doctrinal, que el partido al que le era confiada por decisión regia la acción gubernamental y organizaba los comicios ganara las elecciones para gozar de estabilidad parlamentaria $^{19}$. Por tanto, las generales y municipales celebradas en 1899 no fueron una excepción a esta tónica general. Ambas convocatorias, en función de las convenciones que marcaba el turnismo, estaban concebidas para proporcionar la mayoría suficiente de gobierno a los silvelistas tanto en el Parlamento como en los ayuntamientos y la diputación provincial. Siguiendo esta lógica procedimental, la reina regente firmó el decreto de disolución de las Cortes a comienzos de año. La celebración de las elecciones a Cortes quedó fechada en la segunda quincena de abril.

Antes de analizar el escenario electoral, la irrupción de La Liga Agraria y la ruptura de la combinación oficial que provoco su entrada en la arena política, es necesario, con el fin de calibrar su impacto y poder poner en perspectiva los hechos, tener en consideración una serie de elementos de orden general para una mayor comprensión. En primer lugar, que los cauces de la representación entre electores y elegidos estaban mediatizados por la particular geografía electoral establecida en la ley electoral de 1890. Esta disposición distribuía las circunscripciones provinciales en distritos uninominales rurales junto a otros que elegían varios diputados formados por las principales ciudades y localidades de su entorno ${ }^{20}$. La normativa, que estaba concebida en origen para favorecer a los dos grandes partidos al "ruralizar" los distritos en las que se situaban las capitales provinciales, facilitaba los amaños caciquiles del proceso electoral, siempre más factibles en los núcleos de población más pequeños. Pues bien, en correspondencia a su número de habitantes, el distrito en el que se insertaba Granada respondía al modelo dibujado por la ley electoral de 1890 de una ciudad circundada por las localidades adyacentes en el que se elegían varios diputados ${ }^{21}$.

En segundo lugar, conectado con lo anterior y no por ello de menor trascendencia, hay que señalar los poderosos condicionantes relativos a la praxis y cultura política existentes, que dificultaban la entrada en escena de una formación ajena a los partidos del sistema que pudiera disputar su hegemonía. En este sentido, no se puede soslayar el exhaustivo control que de la esfera social y pública

\footnotetext{
${ }^{19}$ Sin duda, como señala Dardé, fue Cánovas el principal inspirador de este principio. En primer lugar, con el objeto de alejar a los militares de la escena política y evitar que un solo grupo monopolizadora el poder. En segundo lugar, ante la inexistencia de un verdadero cuerpo electoral que aupara o derribara ministerios; por lo que, había que crear de manera artificiosa las mayorías necesarias para auspiciar la acción de gobierno. Carlos DARDÉ MORALES, “El comportamiento electoral en España, 1875-1923, (versión corregida), XVIII International Congress, Latin American Studies Association, Atlanta (Georgia), 10-12/3/1994, pp.1-23. https://www.ucm.es/data/cont/docs/297-2013-07-29-2-96 vol1 Darde.pdf
}

\footnotetext{
${ }^{20}$ La ley electoral del 90, pese a ensanchar el cuerpo electoral, no supuso ninguna modificación en cuanto a los principios rectores en los que se aposentaba la anterior ley de 1878; puesto que, siguió manteniendo los mismos cauces de elaboración del censo, idéntica distribución electoral y consolidó el protagonismo de los alcaldes en todo el proceso. Véase a este respecto Miguel MARTíNEZ CUADRADO, Elecciones y partidos políticos en España (1868-1931), II volúmenes, Madrid, Taurus, 1969; Alicia YANINI MONTES, "La manipulación electoral en España: sufragio universal y participación ciudadana (1891-1923)”, Ayer, №3, pp.99-114; Rosa Ana GUTIERRÉZ, Rafael ZURITA y Renato CAMURRI (eds.), Elecciones y cultura política en España e Italia (1890-1923), Valencia, Universidad de Valencia, 2003; Roberto VILLA GARCÍA, España en las urnas: una historia electoral (1810-2015), Madrid, La Catarata, 2015.

${ }^{21}$ Las localidades que componían el distrito pertenecían en su gran mayoría a la comarca de la Vega. Sin embargo, se le agregaron varios municipios bastante alejados de la capital; acaso, el caso más destacado de esta anomalía fuera la inclusión de Zafarraya, localidad lindante con la provincia de Málaga, cuya distancia con Granada era de ochenta y cinco kilómetros.
} 
realizaban los partidos tradicionales, ejercitado en función de la articulación de una vasta red de intereses clientelares. Su plasmación en el plano electoral provocaba dos efectos adicionales. Por un lado, un extendido uso de las prácticas caciquiles sustentadas en el sistemático falseamiento del derecho del sufragio, ejemplificado en el ilícito comercio en la compra de votos, adulteración en los recuentos, y por último, en la confección de las famosas actas en blanco. De otra parte, con consecuencias más perversas, si cabe, el mayoritario alejamiento e inhibición del electorado en la cita con las urnas, asqueado y desengañado por las impurezas del sistema ${ }^{22}$. Una muestra de la atmosfera general que se respiraba a finales de siglo, queda retratado en el siguiente suelto publicado por la prensa:

"El próximo domingo es el día señalado para la votación de los diputados a Cortes que han de representar a esta provincia en las futuras Cámaras [...] Una vez más presenciaremos el triste espectáculo que nos ofrecen los que se llaman políticos, cometiendo sin el menor escrúpulo, una serie inacabable de falsificaciones; veremos personas honradas, poniendo su firma al pié de actas cuya falsedad les consta; alcaldes y gobernadores, cometiendo sin recatarse, el delito de exigir y recoger actas en blanco, para falsificarlas luego cómodamente y según las exigencias de la respectiva combinación”23.

Sin embargo, a pesar de los obstáculos existentes con la finalidad de beneficiar los intereses del bloque de poder en el terreno electoral, la Liga Agraria decidió concurrir a las elecciones a Cortes del 16 de abril de 1899. La responsabilidad recayó en la prestigiosa figura del Conde Benalúa, que a la postre fue la única candidatura independiente que se presentó por el distrito en oposición a la combinación ministerial compuesta por dos conservadores y un liberal. Esta eventualidad, inédita hasta entonces, que abría la posibilidad de iniciar un nuevo tiempo político, suscitó una vibrante corriente de opinión en el distrito favorable a los agrarios. Dicha simpatía terminó por espolear al electorado, que otorgó con sus votos a Benalúa una de las tres actas en disputa ${ }^{24}$. La ruptura de la combinación, por vez primera, supuso la derrota de los dos candidatos liberales que se presentaron. Circunstancia que motivó una catarata de críticas, en las que los fusionistas granadinos acusaron abiertamente de traición a Silvela por no haber respetado los términos del acuerdo electoral.

Las diferencias entre los partidos del turno en Granada se acrecentaron un mes después con motivo de la celebración de las elecciones. La cita con las urnas, cuyo objeto era la renovación parcial del consistorio, solía realizarse con una periodicidad cuya media no excedía los dos años, según determinaba la Ley de Régimen Municipal. El pleno del ayuntamiento se constituía de treinta y nueve

\footnotetext{
${ }^{22}$ El estudio del caciquismo y el clientelismo político ha generado por sí sola una extensísima literatura en paralelo al análisis del periodo restauracionista. Sin ánimo de ser exhaustivo. José VARELA ORTEGA, Los amigos políticos. Partidos, elecciones y caciquismo en la Restauración. 1875-1900, Madrid, Alianza Editorial, 1977 y El poder de la influencia. Geografía del caciquismo en España (1875-1923), Madrid, Centro de Estudios Constitucionales, 2001; Javier TUSELL, Oligarquía y caciquismo en Andalucía, 1890-1923, Barcelona, Planeta, 1976 y La crisis del caciquismo andaluz, 1923-1931, Madrid, Cupsa, 1977; Joaquín ROMERO MAURA, "El caciquismo: Tentativa de conceptualización", Revista de Occidente, № 127, 1973, pp.15-44 y "El caciquismo como sistema político" en Ernest GELLNER (coord.) Patronos y clientes, Barcelona, Júcar, 1986; Antonio ROBLES EGEA (coord.), Política en penumbra: patronazgo y clientelismo político en la España contemporánea, Madrid, Siglo XXI, 1996; Salvador CRUZ ARTACHO (coord.), Andaluces contra el caciquismo: la construcción de una política democrática en la Restauración, Sevilla, Centro de Estudios Andaluces, 2013.

${ }^{23}$ El Defensor de Granada, 23-3-1898, "Las elecciones".

${ }^{24}$ Manuel TITOS MARTíNEZ, Rodríguez Acosta..., op.cit, pp.249-251.
} 
concejales que eran elegidos para un periodo de cuatro años, desempeñando uno de ellos por designación real el cargo de Alcalde-Presidente. La proporcionalidad escogida en cada renovación no seguía una simetría fija, oscilando entre diecinueve y veintiún concejales. La distribución del electorado se hacía en función de nueve distritos, en virtud de la ordenación del entramado urbano que era de carácter parroquial.

Los liberales, después de los desalentadores resultados obtenidos en las generales, intentaron cerrar un pacto con Mariano Agrela, jefe de los silvelistas locales, y el gobernador civil, para que no hubiera lucha y se llegara a un reparto de actas favorables. La medida no prosperó, no solo porque los azucareros de La Liga Agraria decidieron concurrir a las municipales con absoluta libertad de acción frente a los arreglos gubernamentales, sino también, y esto fue lo que acrecentó el malestar latente, por la escasa predisposición de los conservadores para el acuerdo. En esta desconcertante resolución, influyó la indudable división a la que estaba sometido el propio Partido Conservador, fraccionado en silvelistas, tetuanistas y romeristas. Tampoco favoreció la avenencia la aparición de las primeras grietas dentro del Partido Liberal, pues a los comicios de mayo, finalmente, se presentaron varios candidatos de filiación gamazista y una facción de liberales independientes. Las posibilidades de llegar a un arreglo se hicieron impracticables. Los resultados de la consulta dibujaron un escenario atípico, caracterizado por la atomización del pleno en una pléyade de grupos en la que los silvelistas quedaron en franca minoría. A ello se sumó la irrupción de La Liga Agraria, que consiguió tres asientos en el consistorio. Ante el revés obtenido, los conservadores de Silvela intentaron anular la convocatoria electoral, cuestión que no consiguieron. Debido a este fracaso, como luego tendremos ocasión de ver, esperaron la oportunidad favorable para hacer virar la política municipal en provecho propio.

Cuadro 1. Elecciones municipales del 14 de mayo de 1899

\begin{tabular}{lc}
\hline Partidos Políticos/Facciones & Concejales \\
\hline P. Conservador/ Silvelistas & 3 \\
P.Conservador/ Tetuanistas & 3 \\
P.Conservador/ Romeristas & 2 \\
P. Liberal & 2 \\
P.Liberal/ Gamacistas & 2 \\
P.Liberal/ Independientes & 3 \\
Liga Agraria (Azucareros) & 3 \\
Republicanos Nacionales & 3 \\
Total & 21 \\
\hline
\end{tabular}

Fuente: Elaboración propia a partir de los datos aparecidos en El Defensor de Granada, 15-5-1899, "Las elecciones".

\section{LA REBELIÓN DE LOS INDUSTRIALES DEL AZÚCAR}

El proceso de erosión de la legitimidad que atesoraban los silvelistas en el gobierno municipal, a raíz de del varapalo sufrido en el plano institucional en las elecciones locales por la imposibilidad de cerrar una combinación favorable, se acrecentó a finales del mes de mayo con los prolegómenos de una protesta en la esfera social que estallaría con estrépito en el verano. La campaña estuvo motivada por la decisión del ministro de Economía y Hacienda, Raimundo Fernández Villaverde, de promulgar una ley 
que propiciaba la liberalización del sector del azúcar, permitiendo la entrada de azucares foráneos sin restricción o arancel alguno que los gravase. Las movilizaciones en favor de su derogación fueron capitaneadas por los industriales de la Liga Agraria, y comenzaron con la presentación de un colosal artículo a toda página en el diario El Defensor. Su objeto fue el de implicar al conjunto de la ciudadanía, en tanto en cuanto no se podía permitir que "se socavara el prestigio y la prosperidad de Granada" 25 .

Sin dejar de ser del todo cierto, detrás de las grandilocuentes frases que se pronunciaron en contra de la ley, se ocultaban los verdaderos perjudicados por la medida: los grandes industriales azucareros y financieros. Los inicios del cultivo de la remolacha en España estuvieron ligados a la Vega de Granada, donde en 1882, Juan López-Rubio Pérez construyó la primera fábrica de azúcar remolachero del país ${ }^{26}$. Pese a que los inicios no fueron fáciles para la industria nacional (grandes exigencias técnicas del cultivo, las presiones de los intereses antillanos que veían amenazadas sus exportaciones a la metrópoli y la competencia europea), en 1892 se habían creado dieciséis ingenios en todo el territorio nacional, de las que diez estaban ubicados en la Vega. En 1898, en coincidencia con la pérdida las colonias, la producción nacional ascendía a 76.500 toneladas, de las que 52.800 eran de remolacha y 23.700 de caña, cantidad más que suficiente para atender el consumo interno que en ese año ascendió a 81.500 toneladas $^{27}$.

Con este escenario, la pérdida de las posesiones de ultramar no debería haber producido grandes modificaciones, por cuanto la capacidad de producción superaba la demanda. Ante esta situación Villaverde planteó una reforma del impuesto sobre el azúcar, que se constituía como una verdadera ordenación del mercado azucarero nacional ${ }^{28}$. El objetivo era que el mercado se autorregulara y evitar una superproducción; sin embargo, no contaba con los enormes desajustes que podían provocar en el tejido fabril ya instalado y en la mano de obra asalariada que requería ${ }^{29}$. En esta convergencia de intereses diversos se encontraban también los labradores de la Vega: pequeños propietarios de la tierra que había comenzado a cultivar las simientes, encontrando una fuente de ingresos seguros y con una rentabilidad creciente. De esta manera, de una forma u otra, la nueva regulación terminó afectando a todos los sectores sociales.

La comisión gestora de las reivindicaciones llevó a cabo su primera acción de protesta el 24 de mayo, en una asamblea a puerta cerrada en el Teatro Isabel la Católica. A su salida, se verificó una majestuosa manifestación compuesta por entre doce y quince mil personas que concluyó a las puertas del Gobierno Civil, donde se hizo entrega de la exposición de motivos que se iba a remitir a la

\footnotetext{
${ }^{25}$ El Defensor de Granada, 24-5-1899, "A los granadinos".

${ }^{26}$ Los orígenes del cultivo en María del Carmen OCAÑA OCAÑA, La Vega de Granada, Madrid, Instituto de Geografía Aplicada al Patronato Alonso Herrera, 1974.

${ }^{27}$ Manuel MARTín RODRÍGUEZ, Azúcar e intervención económica en España. La fábrica azucarera San Isidro, 19041984, Granada, Universidad de Granada, 2009, p.16.

${ }^{28}$ El impuesto sobre la fabricación era de un tipo único de 25 pesetas por cada 100 kilogramos, común para el azúcar de remolacha y de caña con el fin de no discriminar fiscalmente a ninguna de las dos actividades. Los entresijos de la ley en Manuel MARTín RODRÍGUEZ, "El impuesto sobre el azúcar de 1899 y su incidencia sobre la industria azucarera española”, Hacienda Pública, № Extra, 1999, pp.153-164.

${ }^{29}$ Entre 1882 y 1904, la industria azucarera creó 63.963 puestos de trabajo que sumados a los 32.747 en el campo, da sobrada cuenta del impacto social del cultivo en la época. Los datos en Manuel MARTín RODRÍGUEZ, Azúcar y descolonización. Origen y desarrollo de una crisis agraria en la Vega de Granada. El ingenio de San Juan, 18821904, Granada, Universidad de Granada, 1982, pp.298-299.
} 
presidencia. En estos compases iniciales, en las que las movilizaciones fueron encabezadas por el grueso de las fuerzas vivas de la ciudad (los diputados a Cortes por el distrito, el representante del Arzobispo, importantes propietarios), las movilizaciones contaron con la presencia y apoyo del alcalde, el silvelista Manuel Tejeiro ${ }^{30}$. Circunstancia que no volvería a repetirse, pues tanto los diputados adictos como el primer edil, dejaron de secundar las acciones de protesta propuestas por la comisión cuando estas comenzaron a radicalizarse.

En julio, un mes después, ante la falta de interés del ministro de Hacienda en rectificar los términos del proyecto, los organizadores llamaron a un paro de actividad y cierre patronal en los ingenios azucareros hasta que no se llegara a una solución adecuada a las demandas presentadas. Pero, acaso, la medida más efectiva para forzar una negociación fue la de "invitar a los labradores para que intervengan en esta gestión, la cual debe llevarse al límite de lo que humanamente sea posible". ${ }^{31}$

La acción, que demostró con toda crudeza su efectividad, tenía por objeto la movilización de los representantes más reputados en las zonas rurales con el fin de atizar el fantasma del desempleo entre el campesinado, y, por ende, del hambre. A finales de mes, las localidades de Pinos Puente, Gabia Grande y Chauchina celebraban masivas concentraciones en las que el vecindario con gran exaltación pedía la retractación del Gobierno. La escenificación de la protesta quedó reflejada en esta carta remitida por un testigo presencial de los hechos al director de un rotativo local:

"Los labradores del distrito, que siempre se han distinguido por su religiosidad en el pago de cuanto absurdo impuesto crean muchos sapientísimos gobiernos, se ha indignado hasta el punto laquí cosa inaudita) se han congregado, y en imponente manifestación de protesta, a la que han asistido absolutamente todos los labradores y el vecindario en masa en la tarde de este día, han recorrido la población [...] pero lo que no sabrá usted es la rabiosa indignación de que se hallan poseídos todos los labradores de esta zona al considerar el porvenir que puede presentárseles, y sobre todo el afán inconsiderado o imbécil de nuestros gobiernos de matar en flor cuantas industrias se implantan que mejoran el país como acontece con la azucarera"32.

La velada invitación a la acción encubría una incitación al motín. La semana concluyó con disturbios en Fuente Vaqueros, Cúllar Vega, Alhendín, Armilla, Asquerosa y Cijuela, en la que los manifestantes recorrieron la población entre gritos de abajo el Gobierno y mueras a Villaverde. En Láchar se produjeron varios disparos, y solo las llamadas a la calma del alcalde pudieron apaciguar los ánimos. Varios días después se repitieron concentraciones y marchas en otros pueblos de la Vega ${ }^{33}$. Mientras tanto, en Granada, la asamblea opositora a la ley de liberalización del azúcar en unión con la Cámara de Comercio llamó a la huelga general. El paro se verificó el 27 de julio, concluyendo la jornada con cargas policiales y quema de fielatos. En simultaneidad, la comisión nombró la junta que debía desplazarse a Madrid, compuesta en su gran mayoría por los flamantes miembros de la Liga Agraria: Santiago Oliveras, Juan López-Rubio y los concejales e industriales, Salvador Montoro y Francisco Sánchez Echevarría.

\footnotetext{
${ }^{30}$ El Defensor de Granada, 25-5-1899, "La manifestación”.

${ }^{31}$ El Defensor de Granada, 20-6-1899, "La ruina de Granada".

${ }^{32}$ El Defensor de Granada, 23-7-1899, Carta al director.

${ }^{33}$ La sucesión de acontecimientos puede seguirse en El Defensor de Granada, 23-24-25-7-1899.
} 
Debido a estas circunstancias, en conjunción con los altercados que se habían producido en otros puntos de España, Villaverde se vio obligado a negociar con la Junta General Azucarera Nacional. La reunión, que tuvo lugar el 4 de octubre de 1899, contó con la determinante presencia del Conde de Benalúa (diputado a Cortes de la Liga), que se encargó de pactar las condiciones en representación de todas las fábricas del sur y del mediodía de España. La resolución, si bien no recogió la totalidad de demandas presentadas por los azucareros, fue una victoria moral, ya que consiguió restringir el acceso ilimitado de azucares extranjeros al mercado patrio y flexibilizó el pago en las hojas de adeudo del impuesto que pasaron de quincenales a mensuales ${ }^{34}$. En el plano local, señaló el punto álgido del poder de influencia alcanzado por los agrarios en la esfera municipal.

\section{LA INHABILITACIÓN DE LOS OPOSITORES}

Bajo este adverso panorama para los silvelistas granadinos, que además solo contaban con siete miembros en el pleno para afrontar los dos siguientes años de mandato tras la verificación de las elecciones parciales de mayo ${ }^{35}$, la desunión entre sus miembros, así como las críticas hacía el jefe provincial, no tardaron en aflorar. A comienzos de otoño, un correligionario del partido remitía una carta al jefe de la facción, el Marqués de Portago, en coincidencia con una visita de este a Granada, en la que le ponía al corriente de la "grave enfermedad que el partido padece". La única solución, a juicio de su interlocutor, era que el Marqués se pusiera al frente de la organización y revirtiera el ridículo que se estaba haciendo. En la larga misiva, se quejaba amargamente de que la desorientación reinante hubiera impedido realizar el conveniente acopio de cargos públicos y la anulación de los comicios municipales.

"Usted es diputado por la circunscripción y sabrá que en toda olla, no hay ni un ayuntamiento que sea genuinamente silvelista; usted sabrá que en la Diputación Provincial no se ha hecho la más pequeña variación, ni aun siquiera lo que ha sido siempre práctica constante, la variación del presidente; que en los centros oficiales no se nos hace caso; [...] Ni un solo puesto del ayuntamiento está ocupado por silvelistas [...] Es una desdicha tremenda la de los silvelistas: aquí le cierran las puertas en todas partes; acuden a Madrid con un mensaje al Presidente del Consejo de Ministros y hace tres meses que están esperando la contestación; piden la nulidad de las elecciones de Granada y ese infelicísimo jefe que se llama Conde de Agrela, dice que él no tiene interés en tal cosa [...] iDesdicha mayor no se ha visto!"36

Sumidos en la mayor de las confusiones, los representantes locales del partido gobernante, que abogaban por una pronta reorganización del ayuntamiento que diera cumplida cuenta de sus apetencias político-administrativas, consiguieron su objetivo a fines del mes de noviembre. El pretexto empleado se presentó, de manera casual, en virtud de unas manifestaciones en el Congreso del diputado silvelista por el distrito de Órgiva José España Lledó, en las que afirmaba que Granada era un foco de defraudadores del Estado. Según sus declaraciones, en la calle Reyes Católicos, a la que

\footnotetext{
${ }^{34}$ Los términos del acuerdo en El Defensor de Granada, 8-10-1899, "Los azucares".

35 La composición final del nuevo ayuntamiento tras los comicios bianuales arrojó la siguiente composición: Conservadores/Silvelistas (7), Conservadores/Tetuanistas (7), Conservadores/Romeristas (3), Liberales/Sagastinos (6), Liberales/Gamazistas (4), Liberales/Independientes (3), Republicanos Nacionales (6), Liga Agraria (3).
}

${ }^{36}$ La Publicidad, 18-10-1899, “Carta abierta. Al Excmo. Sr. Marqués de Portago". 
calificaba de centro del comercio de lujo de la ciudad, no abonaban el impuesto de la contribución más que siete industriales, eludiendo los restantes el pago mediante actas falsas.

Las declaraciones, que fueron tachadas de calumniosas por los concejales de las minorías, fueron desmentidas en pleno mediante la presentación de un completo memorándum basado en datos oficiales $^{37}$. En virtud de la falsedad de los hechos, y para que el buen nombre de la ciudad quedara donde le correspondía, los opositores presentaron una proposición para que el cabildo telegrafiara a los diputados de la circunscripción para que hicieran constar una rectificación del Diario de Sesiones y un voto de censura del diputado España.

La moción dio lugar a una tensa discusión entre ministeriales y los representantes de las minorías en torno a la naturaleza de la propuesta. Pues, los silvelistas juzgaban que se había entablado una discusión esencialmente política que escapaba de la esfera de acción económica que el ayuntamiento le correspondía conocer. Por tanto, estaba fuera de la ley cualquier deliberación pudiendo incurrir en un delito penal ${ }^{38}$. Acto seguido emitieron un voto particular y se retiraron del salón de plenos.

En representación de la oposición, el republicano Perales impugnó la propuesta haciendo hincapié en el carácter económico-administrativo de la deliberación, ya que el impago suponía un recargo en las cuotas municipales para los industriales. Los catorce concejales de las minorías terminaron aprobando la moción presentada ${ }^{39}$. En las postrimerías del año, a instancias del gobernador civil, el ministro de la Gobernación, Eduardo Dato, suspendía por real orden a los ediles que tomaron el acuerdo $^{40}$. La medida fue ejecutada en aplicación del artículo 189 de la Ley de Régimen Municipal que exponía las causas de suspensión de ayuntamientos, alcaldes y tenientes en caso de insubordinación, disposición que incluía en su segundo párrafo "la extralimitación grave con carácter político" ${ }^{41}$.

\section{El contexto nacional en torno al 98. Los vicios del sistema.}

Antes de emprender el relato de los hechos que dieron curso a la protesta, no puede soslayarse que estuvieron propiciados, a su vez que insertados, dentro del marco favorable que dibujó el espíritu crítico regeneracionista que demandaba una mayor democratización del sistema y que venía operando

\footnotetext{
${ }^{37}$ El documento mostraba que en la última liquidación trimestral del impuesto de contribuciones en el plazo voluntario, eran noventa y cuatro los industriales y comerciantes que habían satisfecho sus obligaciones con el fisco; elevándose la cantidad total a la respetable cifra de siete mil novecientas cincuenta y seis con cincuenta céntimos.

${ }^{38}$ Se referían a la Real Orden Circular de 16 de Octubre de 1894. En dicha disposición se aclaraba que diputaciones y ayuntamientos solo estaban facultados para votar libremente los asuntos sometidos a sus competencias.

${ }^{39}$ ARCHIVO MUNICIPAL DE GRANADA (AMG), Actas de la Comisión Municipal Permanente, L.00239, 25/11/1899, pp.301-306.

${ }^{40}$ Los concejales separados de su cargo fueron: José Gómez Tortosa, Enrique Sánchez, Juan Horqués, Luis Sansón, Rafael García-Duarte González, Pablo Perales, Salvador Montoro, Aurelio Álvarez, Antonio Sánchez Gallardo, Francisco Sánchez Echevarría, Juan Ramón La Chica y Mingo, Carlos Afán de Rivera, Torcuato López. El Defensor de Granada, 30-12-1899, "La política local”.

${ }^{41}$ El artículo estaba recogido en el capítulo I del título $V$ que hacía referencia a los "Recursos y responsabilidades que nacen de los actos de los ayuntamientos". La Ley de Régimen Municipal en Gaceta de Madrid, (4-10-1877), №277, Tomo IV, p.45.
} 
con inusitada fuerza desde comienzos de la última década del siglo $\mathrm{XIX}^{42}$. En este sentido, la profunda crisis política y social desencadenada tras el Desastre del 98, por una parte, amplificó y potenció la discusión de una problemática que procedía de antaño; de otro lado, puso en primer plano y señaló la urgente necesidad de reforma de la administración local, al erigirse en el elemento clave para la regeneración y moralización de la vida pública en España.

Con la Restauración, se consolidó un modelo político-administrativo centralista y uniforme: restricción inicial del sufragio (modificado en 1890 con la concesión del sufragio universal masculino), libre disposición en el nombramiento de alcaldes, intervención gubernamental en materia local de presupuestos. Bajo esos férreos principios el municipio quedó de facto bajo la tutela del Estado, estando limitadas sus decisiones por una inspección y supervisión de sus actuaciones de carácter permanente. Dichas líneas generales de subordinación a la administración estatal quedaron sancionadas por la Ley de Régimen Municipal de 1877 y la Ley de Régimen Provincial de 1882.

Sin embargo, tras esta imagen uniformadora de un Estado omnipotente fiscalizador del conjunto de las actividades locales, se ocultaba una total libertad de las élites locales. Su consecuencia directa fue la configuración de un régimen representativo controlado electoralmente por los distintos notables que operaban en cada distrito, ya fuera empleando medios legales (el encasillado) o de manera ilegal (manipulación de los censos, compra del voto o alteración en el recuento). Debido a su incapacidad para imponer su autoridad, el régimen liberal emanado de la monarquía restaurada optó por legitimar su hegemonía integrado a los jefes locales en extensas redes clientelares, cuyo epicentro radicaba en la capital del Reino. La confección de las mayorías parlamentarias favorables al gobierno de turno, quedaban bajo el auspicio de varias figuras que hacían las veces de intermediarios. Entre ellas, el gobernador civil tenía una posición predominante, al constituirse en el facilitador de la acción de gobierno en la provincia, el distrito o el municipio, vertebrando la relación con caciques y alcaldes.

A nivel local, la resultante de este proceso clientelar orientando hacia la continua fabricación de mayorías adictas a los intereses del partido dinástico en el gobierno, provocaba la constitución de ayuntamientos en donde el vecindario no tenía ni "arte ni parte". La representatividad, la elección de concejales y la articulación del pleno municipal eran un fraude, y el principio de soberanía popular quedaba elevado a la categoría de mito. De ahí que la ansiada revitalización de la vida nacional anhelada por la vía regeneracionista, y expresada con intensidad creciente desde la tribuna, el ateneo, pasando por la columna de prensa en los años finiseculares, transitara de manera indefectible por una transformación de arriba a abajo del municipio ${ }^{43}$. Pues bien, en gran medida, estas palpitantes cuestiones que viciaban y falsificaban el marco político-institucional del sistema liberal, gravitaron en todo momento en el debate establecido en torno al caso de la suspensión gubernamental de los ediles del Ayuntamiento de Granada.

\footnotetext{
42 Los obras más destacadas pertenecen a Lucas MALLADA y PUEYO, Los males de la patria y la futura revolución española: Consideraciones generales acerca de sus causas y efectos, (1a edición 1890), Madrid, Fundación Banco Exterior, 1990; Ángel GANIVET, Idearium español, (1ạ edición 1898), Granada, Diputación Provincial de Granada, 1993; Ricardo MACÍAS PICAVEA, (1a edición 1899), El problema nacional, Madrid, Fundación Banco Exterior, 1992; Joaquín COSTA, Oligarquía y caciquismo: como la forma actual de gobierno en España; urgencia y modo de cambiarla (1a edición 1901), Madrid, Biblioteca Nueva, 1993.

${ }^{43}$ Un interesante estudio y antología de textos relacionados con las propuestas más sobresalientes de reforma de la Ley de Régimen Municipal durante la Restauración, en Antonio ROBLES EGEA (edición y estudio preliminar), Política y régimen local en la crisis de fin de siglo, Granada, $\mathrm{CEMCl}, 1998$.
} 


\section{La protesta en favor de la reposición de los concejales}

El episodio de protesta dio comienzo a principios de 1900, extendiéndose durante un periodo que se alargó durante diez meses, de enero a octubre. En cuanto a su intensidad, se distinguió por desarrollarse a lo largo de dos etapas bien diferenciadas. Una de carácter inicial, que coincidió con el ciclo alcista de la disputa, en la que se concentró el grueso de las acciones patrocinadas por los sancionados y sus favorecedores en descargo por su injusto cese. En esta primera fase, en paralelo y como reacción al respaldo ciudadano recibido por los concejales desplazados de su cargo, se desató una serie de dimisiones de destacados miembros del Partido Silvelista que desestabilizaron aun más a la formación. En el plano institucional, fruto de la dejación de funciones y nefasta gestión del municipio de los ministeriales, condujo a una preocupante crisis social por la paralización de las obras de la Gran Vía, que proporcionaban abundante oferta de empleo entre el elemento obrero. La secuencia de los hechos concluyó a finales del mes de abril con el sobreseimiento temporal de la causa que se seguía contra los concejales del ayuntamiento.

En segundo término, revistiendo tintes poco acusados, desde esa fecha hasta octubre, el tanto de culpa que recaía sobre los representantes del cabildo pasó a dirimirse en exclusiva por cauces jurídicos, al recurrir José España Lledó al Tribunal Supremo la sentencia dictaminada por la Audiencia Provincial. La contienda finalizó con la emisión de sentencia favorable por el alto tribunal, concediendo la razón a los afectados y revocando la suspensión. En honor a la decisión judicial, los protagonistas de la controversia celebraron un acto colectivo, en el que reafirmaron sus posturas y dieron las gracias de manera pública al Conde de Benalúa por su defensa de la ciudad.

Dentro de esta concepción general de las características más destacadas de las que se revistió el episodio de protesta, queda por mencionar dos cuestiones de suma importancia para poder comprender con cierto rigor su alcance. La primera está relacionada con el grado de implicación y apoyo recibido a las demandas elevadas por los concejales suspendidos a la ciudadanía. A este respecto, las adhesiones quedaron circunscritas durante todo el proceso al ámbito de las clases mercantiles y el comercio de Granada. Pues, frente al fervor y entusiasmo demostrado por los industriales capitalinos, el obrerismo permaneció ausente, manifestando un mutismo absoluto sobre el asunto ${ }^{44}$. Asimismo, como segundo punto, en función de la clara orientación mesocrática que adoptó el movimiento de opinión, el repertorio de contestación empleado remitió a los cauces de sociabilidad en los que se desenvolvía la política oligárquica de la Restauración: el banquete y la campaña de prensa.

La exposición pública de los agravios cometidos contra los concejales defenestrados y de sus reivindicaciones, partió de un grupo de representantes del comercio, la industria y de independientes, que en su mayor parte no pertenecían a ningún partido "salvo el de Granada". La idea, que se gestó en poco tiempo y cosechó con prontitud una numerosísima lista de adhesiones, se materializó con la celebración de un majestuoso banquete en el Teatro Alhambra el día de la festividad de los Reyes Magos de 1900. La asistencia desbordó las previsiones de los convocantes, contando el ágape con la

\footnotetext{
${ }^{44}$ El 7 de enero de 1900, en simultaneidad con el inicio de la protesta, se constituyó la sociedad de obreros de "La Obra" (1900-1906), primer movimiento societario que aglutinó en su conjunto a todos los gremios de Granada y al Partido Socialista. En ninguna de las charlas, conferencias o exposiciones que ofreció aquel año, se hizo la menor alusión al contencioso que sostenían los ediles con el ministerio de la Gobernación. Álvaro LÓPEZ OSUNA, Dinámica de la contienda política..., op.cit, pp.295-307.
} 
presencia de más de trescientos comensales. La convocatoria alcanzó gran publicidad nacional al ser cubierta por los corresponsales de los diarios madrileños de más importancia y tirada ${ }^{45}$.

Como solía ser habitual, a los postres comenzaron los brindis, momento en el que los concejales sancionados dirigieron a los asistentes varios discursos. Los intervinientes coincidieron de manera unánime en expresar que su caída había sido honrosa y a plena satisfacción, pues era obligado defender los intereses y el honor de los productores granadinos. Sin embargo, tras este acentuado tono de unánime censura a la actuación gubernamental, deslizaron una serie de críticas que conectaban con el clima general de rechazo regeneracionista y noventayochista a la "España oficial".

Entre ellas, destacaron las realizadas por Juan López Rubio-Pérez, que atacó los fundamentos mismos del sistema político de la Restauración. En primer término, en función del caciquismo electoral imperante, afirmando ante el auditorio que, "la verdadera causa de la suspensión no tenía otro objeto que llevar al ayuntamiento gubernativamente una mayoría silvelista que no pudo llevar en las últimas elecciones". En segundo lugar, en razón a los corruptos intereses administrativos con los que se repartían puestos, cargos y sueldos entre correligionarios y adictos en el consistorio; ya que, "si el gobierno quería hacer vacantes para sus amigos en el municipio, debió buscar otro pretexto". Por último, de soslayo, aludió a la parcial política de orden público implementada por el ministerio de la Gobernación contra los industriales de la Liga Agraria por su desafección, al declarar que "las fábricas están militarmente ocupadas por los carabineros". ${ }^{46}$

Por su parte, otro de los concejales "azucareros" presentes, Salvador Montoro, negó la acusación realizada por los ministeriales de que la reunión fuera un acto político; aludiendo a la pluralidad de fuerzas representadas que se extendía desde el republicanismo al carlismo. A su juicio, la protesta carecía de signo partidista, remitiendo a una demanda puramente granadina, más que otra cosa. Mirando a un contexto más amplio, el republicano nacional Rafael García-Duarte afirmó con gran ironía que la suspensión era fruto "de la política regeneradora" aplicada por el Gobierno. La totalidad de los rotativos coincidieron en que el banquete realizado en honor de la minoría municipal apartada de sus funciones, fue el acto público más importante celebrado en Granada en décadas ${ }^{47}$.

\footnotetext{
${ }^{45}$ En cuanto a los diarios de la capital del Reino que cubrieron el banquete fueron los siguientes: El Imparcial, El Liberal, Heraldo de Madrid, El País y El Nacional. De Barcelona cubrió el evento El Diario Mercantil. De la capital nazarí los siguientes diarios, semanarios y revistas: El Defensor de Granada, La Publicidad, El Heraldo Granadino, El Triunfo, El Pueblo, La Verdad, X, La Campana de la Vela, La Alianza, La Pulga, La Unión Escolar, Nuevo Gil Blas, La Alhambra, La Defensa del Comercio, La Gaceta Médica, El Profesorado. En total veintidós rotativos distintos.

${ }^{46}$ Para un análisis del control del orden social y público en la Restauración. Antonio ELORZA, “La ideología liberal ante la Restauración: la conservación del orden”, en La Utopía anarquista bajo la segunda república, precedido de otros ensayos, Madrid, Ayuso, 1973; Eduardo GONZÁLEZ CALLEJA, "La política de orden público en la Restauración”, Espacio, tiempo y forma, UNED, №20, 2008, pp.93-128. De reciente aparición Rafael CRUZ, Protestar en España 1900-2013, Madrid, Alianza, 2015.

${ }^{47}$ Para una reconstrucción de lo acontecido en el banquete se han empleado las crónicas publicadas en Heraldo de Madrid, 7-1-1900, "Protesta granadina"; El Liberal, 8-1-1900, "La protesta de Granada"; El Imparcial, 8-1-1900, "Los concejales de Granada" y El País, 8-1-1900, "Los concejales suspensos".
} 
En clave interna, el descrédito sufrido por el Partido Silvelista ante la opinión provocó la rápida separación de sus filas de varios destacados miembros ${ }^{48}$. Sin embargo, a escala externa, el pleito mantuvo su rumbo invariable al confirmar Eduardo Dato la suspensión gubernativa de los catorce concejales suspensos, a mediados de febrero ${ }^{49}$. La secuencia quedó completada, pocas semanas más tarde, con una comunicación del gobernador civil instando al alcalde a que los concejales interinos se posicionaran de sus cargos ${ }^{50}$. A continuación, libres los elementos ministeriales de cualquier restricción, con el fin de satisfacer los usuales compromisos de partido, ambiciones de mando y favores con los suyos, el ayuntamiento declaró en cesantía a gran parte de los empleados de la administración municipal $^{51}$.

Como efecto adverso de esta coyuntura, derivada de los embrollos y juegos de manos en que estuvo sumida la política local desde las elecciones municipales del año anterior, la ciudad atravesó una crisis de trabajo en los meses siguientes ocasionada por la negligente gestión del consistorio de las obras de la Gran Vía. La ralentización de los trabajos, ocasionada por la paralización de los trámites de concesión de nuevas licencias de edificación, provocó un paro masivo en el gremio de la construcción y adláteres $^{52}$. La situación de penuria terminó afectando al conjunto de la actividad económica, en conjunción con la secular falta de crédito para acometer nuevas construcciones y con la merma de la actividad comercial por la bajada del consumo ${ }^{53}$. En paralelo, a estos acontecimientos, a finales del mes de abril, la sección segunda de la sala de lo criminal de la Audiencia Provincial de Granada dictaba el sobreseimiento de la causa que se seguía contra los catorces concejales del ayuntamiento, por el supuesto delito de injurias a un diputado. De manera adicional, el auto mandaba reintegrar en sus puestos a los defenestrados de sus puestos ${ }^{54}$.

Desde ese momento, el contencioso entró en una segunda fase, al interponer España Lledó ante el Tribunal Supremo un recurso de casación contra el fallo interpuesto por la Audiencia granadina. En octubre, el alto tribunal desestimó el recurso, confirmando el fallo emitido en primera instancia y condenando al diputado silvelista al pago de las costas del juicio. Para celebrar el triunfo obtenido, de

\footnotetext{
48 Abandonaron la agrupación los exdiputados nacionales y provinciales, Francisco Angulo Prados y Manuel González, respectivamente, junto al concejal Ricardo Torres y el abogado Fermín Camacho. El Defensor de Granada, 13-1-1900, "Política local".

${ }^{49}$ En aplicación de los artículos 190 y 191 de la Ley de Régimen Local, que disponían que pasados cincuenta días el Gobierno tendría que tomar una decisión definitiva. En caso de encontrar procedente la destitución, el tanto de culpa pasaría al tribunal o juzgado pertinente. Gaceta de Madrid, (4-10-1877), nำ277, Tomo IV, p.45. La noticia en El Defensor de Granada, 16-2-1900, "Telegramas. Concejales suspensos".

${ }^{50}$ Los concejales sustitutos fueron propuestos en el Pleno Municipal extraordinario de fin de año.AMG, Actas de la Comisión Municipal Permanente, L.00239, 31/12/1899, pp.351-360.

${ }^{51}$ La comunicación del gobernador civil al alcalde en El Defensor de Granada, 2-3-1900, "La cuestión municipal"; las cesantías en El Defensor de Granada, 15-3-1900, "Iniciativas municipales".

52 La apremiante situación que padecía la ciudad fue analizada en sendos artículos de prensa por El Liberal, 26 y 27-2-1900, "La crisis obrera de Granada". Con posterioridad algunos extractos fueron transcritos en El Defensor de Granada, 2 y 9-3-1900, "La crisis obrera".

53 Una descripción de la desconsoladora situación en El Defensor de Granada, 24-4-1900, "La crisis obrera".

${ }^{54}$ La decisión estaba fundada en aplicación del apartado segundo del artículo 637 de la Ley de Enjuiciamiento Criminal, al no constituir delito el hecho que dio lugar al procesamiento. El Defensor de Granada, 29-4-1900, "El proceso de los concejales".
} 
igual forma que a comienzos de año, los ediles celebraron un nuevo banquete, esta vez en el Hotel Alameda y sin asistencia de público. En él los protagonistas, con afectados discursos, agasajaron al Conde de Benalúa por su acción en Cortes en defensa de la verdad y de los productores de la ciudad ${ }^{55}$; coincidiendo, en la legitimidad de sus actuaciones, al ser el único diputado del distrito elegido por el voto popular ${ }^{56}$.

\section{CONCLUSIONES}

Como ha quedado patente, las causas que originaron el episodio de protesta emprendido en Granada a raíz de la suspensión gubernativa de los ediles de la minoría opositora a finales de 1899, tuvieron su génesis en los inesperados desarreglos que acontecieron en la política local. No fueron, por tanto, producto del azar o de una decisión del ministerio de la Gobernación en respuesta a un acuerdo consistorial que ponía en cuestión a un diputado de la mayoría, sino que respondieron a profundas razones de fondo, relacionadas con la propia viabilidad de entramado político-institucional creado por el sistema de la Restauración. En tanto en cuanto no podía permitirse que el partido que había organizado las elecciones, en este caso la Unión Conservadora de Francisco Silvela, no ejerciera el control de la circunscripción y dominara los resortes del ayuntamiento.

A este respecto, dos fueron las cuestiones que operaron y se concatenaron, iniciando la secuencia que propició un nuevo marco de oportunidad política hasta entonces inédito. En primer lugar, la entrada de una nueva agrupación política en la disputa electoral, la Liga Agraria, que consiguió concitar sobre sí en poco tiempo un gran número de apoyos; en segundo lugar, la división interna del Partido Conservador granadino tras la muerte de Cánovas en tres facciones irreconciliables.

Su efecto inmediato, caso de las elecciones generales de abril de 1899, fue la ruptura del encasillado, al acceder el Conde de Benalúa a una de las tres actas del distrito. Con posterioridad, en las municipales de mayo, el fraccionamiento del voto conservador, la consecución de tres puestos por parte de la Liga y los buenos resultados obtenidos por los republicanos, dejó en clara minoría a los silvelistas en el consistorio. El panorama político vino a oscurecerse aun más con la campaña de protesta orquestada y atizada por los "azucareros" contra la política arancelaria de Villaverde en el verano. A finales de año, la situación era insostenible; encontrándose los ministeriales, acosados desde la calle, aquejados de fuertes tensiones internas y a merced de sus oponentes en el cabildo.

De esta forma, la única forma de salvar el inminente bloqueo institucional que se presagiaba por parte de la oposición (una vez agotada la posibilidad de anular las elecciones municipales), fue la de la intervención gubernamental del Ayuntamiento de Granada. Para ello emplearon las prerrogativas que concedía la Ley de Régimen Municipal al ejecutivo central en casos de desobediencia, amparándose en un lesivo acuerdo del consistorio que ponía en solfa la honorabilidad de un diputado de la mayoría. El pretexto, tan pueril como abochornante, dio lugar el inicio de una campaña de repulsa.

\footnotetext{
${ }^{55}$ El Conde de Benalúa fue el único diputado que en sede parlamentaria desmintió las acusaciones lanzadas contra los contribuyentes granadinos. Un ejemplo de su defensa de los comerciantes tomada del Diario de Sesiones del Congreso en El Defensor de Granada, 30-11-1899, "En defensa de Granada". Con posterioridad, se solidarizó con los concejales suspensos por el ministerio de la Gobernación.

56 La crónica del ágape y los discursos en El Defensor de Granada, 30-10-1900, "Un banquete".
} 
La contestación en pos de la reposición de los catorce concejales apartados de sus funciones por defender la dignidad de las clases mercantiles de la ciudad, aunque se publicitó como una acción colectiva que implicaba al conjunto de la ciudadanía, no contó con el apoyo de la clase obrera que fue ajena al asunto. Sus bastiones principales fueron la prensa, El Defensor de Granada, sobre todo, y, en menor medida, El Liberal; y los banquetes, que fueron el altavoz de sus reivindicaciones a nivel local y nacional. Su clientela fue la oligarquía propietaria de los ingenios de la Vega, al ser todos sus ediles suspendidos y sus fábricas vigiladas por las fuerzas de orden público en represalia, y la mediana burguesía comercial que asistió y financió los ágapes.

En cuanto a los objetivos de la protesta en función de su alcance y orientación, hay que distinguir entre dos clases. De un lado, los que podemos calificar o denominar como coyunturales o inmediatos, relacionados con la restitución de los catorce ediles sancionados de su cargo. En cuyo caso, el éxito fue absoluto, ya que se produjo una devolución de sus actas y una decisión judicial favorable que los exoneró del delito de insubordinación y calumnias. Circunstancia que aconteció después de pasar el tanto de culpa por un dilatado periplo procesal que atravesó todas las instancias judiciales.

De otra parte, en referencia a los objetivos estructurales o lejanos que orbitaron en los discursos que se pronunciaron durante todo el episodio de protesta, puesto que en él encontraban sus causas directas, vinculadas al caciquismo, la necesidad de depuración de las costumbres políticas y a la moralización de la administración local, nada se consiguió. El problema era de tal magnitud, debido a que afectaba a los mismos sillares político-institucionales en que se asentaba el régimen canovista, que su solución estaba muy lejos de encontrarse en los buenos propósitos manifestados por los afectados. Como se hizo evidente, en poco tiempo, las llamadas a constituir a un nuevo partido netamente granadino que trajera la regeneración al municipio alejado de banderías políticas e ideologías, no era más que una quimera imposible ${ }^{57}$.

El ejemplo más claro de la imposibilidad de este anhelo, fue la trayectoria seguida por la Liga Agraria. Una vez desaparecidos los motivos coyunturales por los cuales entró en política, el intento de liberalización del sector azucarero, volvió a su función primigenia de referente del asociacionismo patronal. Su neutralización se completó con la cooptación de sus líderes más influyentes por parte de los partidos del turno tradicionales tras la crisis, borrando cualquier mínima esperanza de regeneración del sistema desde dentro. En este sentido, su cabeza visible, el Conde de Benalúa, se pasó al Partido Conservador aceptando una senaduría vitalicia ofrecida por Palacio. Por su parte, el joven Juan Ramón La Chica y Mingo hizo lo propio al ingresar en el Partido Liberal, siendo nombrado alcalde a comienzos de siglo e iniciando una larga carrera política que lo llevo a convertirse en el gran cacique de Granada ${ }^{58}$. En 1902, al igual que unos décadas antes ocurriera con la Liga de Contribuyentes, se disolvió para dar paso a la Cámara Agrícola Provincial.

\footnotetext{
${ }^{57}$ Nos referimos a las declaraciones realizadas por el republicano Pablo Perales en el banquete de octubre de 1900 en el Hotel Alameda. Cuando afirmó: "Aquí se ha formado un núcleo, se ha organizado un partido que empezó a formarse con el decreto de suspensión, un partido en el cual coincidimos todos sean las que fueren nuestras distintas filiaciones políticas, porque el programa esencial de este partido es el bienestar del pueblo granadino". EI Defensor de Granada, 30-10-1900, "El banquete".

58 Juan Ramón La Chica y Mingo fue diputado por el distrito de manera ininterrumpida desde 1905 a 1919. Algunos detalles de su trayectoria en Álvaro LÓPEZ OSUNA y Antonio ROBLES EGEA, "La protesta contra el caciquismo y la contienda política en Granada, 1919”, Historia Social, № 83, 2015, pp.133-156.
} 
Las aguas volvieron a su cauce, de manera definitiva, con la salida de las filas silvelistas de las dos personalidades favorecedoras del contencioso. En el caso del Conde de Agrela, jefe de la facción en la ciudad, porque renunció a su acta de diputado, al verse deslegitimado por sus correligionarios por su falta de liderazgo. Con respecto al polémico José España Lledó, no hizo falta que se sometiera a un proceso de depuración, ya que falleció al año siguiente del fin del caso de la suspensión gubernamental de los ediles de Granada. 